American Journal of Agricultural and Biological Sciences 4 (1): 72-78, 2009

ISSN 1557-4989

(C) 2009 Science Publications

\title{
Biocontrol of Botrytis allii Munn the Causal Agent of Neck Rot, the Post Harvest Disease in Onion, by Use of a New Iranian Isolate of Streptomyces
}

\author{
${ }^{1}$ M. Jorjandi, ${ }^{2}$ G.H. Shahidi Bonjar, ${ }^{3}$ A. Baghizadeh, ${ }^{4}$ G.R. Sharifi Sirchi, ${ }^{2}$ H. Massumi, \\ ${ }^{1}$ F. Baniasadi, ${ }^{2}$ S. Aghighi and ${ }^{5}$ P. Rashid Farokhi \\ ${ }^{1}$ Department of Agricultural Biotechnology, College of Agriculture, Shahid Bahonar University of \\ Kerman, Iran, \\ ${ }^{2}$ Department of Plant Pathology, College of Agriculture, Shahid Bahonar University of Kerman, Iran, \\ ${ }^{3}$ International Center for Science, High Technology \& Environmental Sciences, Kerman, Iran, \\ ${ }^{4}$ Horticultural Research Institute, Shahid Bahonar University of Kerman, Iran \\ ${ }^{5}$ Department of Agronomy and Plant Breeding, College of Agriculture, Shahid Bahonar \\ University of Kerman, Iran
}

\begin{abstract}
Problem statement: Soil Actinomycetes particularly Streptomyces spp. have showed antagonistic activity against wide range of plant pathogens. In the recent decades they have attracted high interests as biocontrol agents. Onion neck rot or gray mold caused by Botrytis allii have imposed economic post harvest damages to onion bulbs and decreased its storage durability and market value. Approach: To investigate for biocontrol means against the pathogen, antagonistic activity of 50 isolates of soil actinomycetes were assayed through agar disk method and dual culture bioassays. Active isolates were exposed to chloroform for detection of antibiotic. Minimum Inhibitory Concentration (MIC) value and solubility of active crude extract in organic solvents were determined for Streptomyces isolate No. 347 which showed a unique and stable property of inhibiting Botrytis allii. To investigate the antagonistic effect of Streptomyces isolate No 347 on control of onion gray mold, four different treatments were tested by means of Tukey HSD test. Results: From the tested isolates, 13 showed anti gray mold activities. Exposure of active isolates to chloroform revealed that Streptomyces isolates No 347, 263 and 350 retained their antifungal activities. The active metabolite(s) of Streptomyces isolate No 347 was polar, soluble in $\mathrm{H}_{2} \mathrm{O}$ but insoluble in chloroform and methanol. MIC of the crude was determined as $0.05 \mathrm{mg} \mathrm{mL}^{-1}$ against $B$. allii. Stability of the active crude in distilled water at room temperature $\left(12-30^{\circ} \mathrm{C}\right)$ was about 6 months. Statistical studies indicated that Streptomyces isolates No 347 can decrease losses of neck rot with significant level $(\mathrm{p}<0.05)$. Conclusion: The future goals include investigation of the antifungal genes in active isolates as candidates for genetic engineering of onion for increased tolerance against B. allii.
\end{abstract}

Key words: Allium cepa, Botrytis allii, antifungal, bioassay, Streptomyces sindeneusis

\section{INTRODUCTION}

Many plants in the genus Allium are known by the common name onion but, used without qualifiers, it usually refers to Allium cepa L. A. cepa is known only in cultivation, but related wild species occur in Central Asia. Onion bulbs contain anti-inflammatory, anticholesterol, anticancer and antioxidant components such as quercetin ${ }^{[1]}$. Botrytis blight or gray mold is a fungal disease which infects a wide array of herbaceous annual and perennial plants ${ }^{[2]}$. This disease may be caused by one or more of the following pathogens;
Botrytis allii Munn, B. squamosa J.C. Walker and $B$. cinerea Pers. The first fungus is the principal species affecting onions in western states of the US. Onion neck rot is primarily a storage disease, although infection originates in the field as leaves and necks mature or are injured and become infected by spores blown from infested onion debris and improperly disposed cull piles. Botrytis air borne spore has been monitored during summer in cultivation arias ${ }^{[3]}$. Sound, bruised and mechanically injured onions can be inoculated with Botrytis allii spores during harvest and from contaminated pallet bins and packing line

Corresponding Author: M. Jorjandi, Department of Agricultural Biotechnology, College of Agriculture, Shahid Bahonar University of Kerman, Iran 
equipment. The spores, however, will germinate only when free moisture is present, such as in bruised and mechanically injured onions or when onions sweat during the warm up period after low temperature storage. Once the spore has germinated Botrytis allii grows mycelia during storage of the onion at low temperatures. Since spread of the fungus is by spores, it is important to reduce the inoculum by sanitizing pallet bins, equipment and storage rooms and then store only sound onions. However, maintaining a low humidity around individual onions during storage is extremely important in reducing infection by Botrytis allii ${ }^{[4]}$.

Streptomycetes are a group of Gram-positive bacteria which are mostly found in the soil; include some of the most common soil life. Streptomycetes produce different kinds of secondary metabolites and biologically active substances of high commercial value such as enzymes (which degrade the fungal cell wall directly) and antibiotics ${ }^{[5]}$. Species in the genus Streptomyces are of the major contributors to the biological buffering of soils and have roles in decomposition of organic matter conductive to crop production. The search for new principles in combating plant pathogens, different from currently used fungicides, is of worldwide concern ${ }^{[6]}$. Approaches to the discovery of new antifungals are generally based on screening of naturally occurring Streptomyces spp. with an ability to produce metabolites having proper bioactivity. At present research 50 isolates of Streptomyces were assayed from which 13 isolates showed high antifungal activity against $B$. allii, the causal agent of onion neck rot. Further in vivo studies indicated that mixed inoculation of Streptomyces isolate No. 347 and B. allii inhibited the disease in onion bulbs. Our ongoing projects include determination and characterizations of the gene(s) involved in the bioactivity of Streptomyces isolate No. 347.

\section{MATERIALS AND METHODS}

Preparation of pathogen: The fungus has been separated from diseased onion and isolated by use of single spore culture. Pure culture prepared and the fungus identified as Botrytis allii.

Pathogenicity test: To prove the pathogenicity of the isolated fungus, spores of 4-6 days grown colony on PDA were placed on pathogen-free bulbs that have been cut on below neck with sterile razor blade under sterile conditions. Inoculated bulbs covered with Parafilm ${ }^{\circledR}$ to prevent dryness and further infections and incubated at $24^{\circ} \mathrm{C}$ for two weeks in capped containers. Controls included uninoculated cut bulbs having no pathogen and kept under similar conditions.
Soil sampling and isolation of Actinomycetes: Soil samples were collected from grasslands, orchards and vegetable fields in different localities of Kerman province, Iran. Several samples randomly were selected from mentioned localities using an open-end soil borer (20 $\mathrm{cm}$ in depth, $2.5 \mathrm{~cm}$ in diameter) as described by Lee and Hwang ${ }^{[5]}$. Soil samples were taken from a depth of 10-20 cm below the soil surface. The soil of the top region (10 $\mathrm{cm}$ from the surface) was excluded. Samples were air-dried at room temperature for 710 days and then passed through a $0.8 \mathrm{~mm}$ mesh sieve and were preserved in polyethylene bags at room temperature before use. Samples ( $10 \mathrm{~g})$ of air-dried soil were mixed with sterile distilled water $(100 \mathrm{~mL})$. The mixtures were shaken vigorously for $1 \mathrm{~h}$ and then allowed to settle for $1 \mathrm{~h}$. Portions $(1 \mathrm{~mL})$ of soil suspensions (diluted $10^{-1}$ ) were transferred to $9 \mathrm{~mL}$ of sterile distilled water and subsequently diluted to $10^{-2}$, $10^{-3}, 10^{-4}, 10^{-5}$ and $10^{-6}$. Inocula consisted of adding aliquots of $10^{-3}-10^{-6}$ soil dilutions to autoclaved CGA $\left(1 \mathrm{~mL}^{-25} \mathrm{CGA}\right)$ at $50^{\circ} \mathrm{C}$ ere considered for each dilution. Plates were incubated at $30^{\circ} \mathrm{C}$ for up to 20 days. From day 7 on, Actinomycetes colonies were isolated on CGA, incubated at $28^{\circ} \mathrm{C}$ for one week and stored refrigerated as pure cultures before use. For screening studies 50 pure Actinomycetes isolates were collected.

Culture media: A synthetic medium, Casein glycerol (or starch) agar (CGA) was used for screening and isolating of Streptomyces ${ }^{[6]}$. Isolated B. allii was grown at $24^{\circ} \mathrm{C}$ and maintained on Potato Dextrose Agar (PDA) (Difco).

Screening procedure and in vitro antifungal bioassays: A- Agar disk-method: Each Streptomyces isolate was smeared on CGA medium as a single streak and after incubation at $28^{\circ} \mathrm{C}$ for $4-6$ days, from wellgrown streaks $6 \mathrm{~mm}$ Agar disks of Streptomyces colony mass was prepared by using sterile cork borers. Disks were then aseptically transferred to PDA plates having fresh lawn cultures of $B$. allii isolate. Controls included using plain disks from CGA medium. Plates were incubated at $24^{\circ} \mathrm{C}$ for $4-6$ days and bioactivity was evaluated by measuring the Diameter of Inhibition Zones (DIZ, mm) ${ }^{[7]}$.

B- Dual Culture Bioassay: Disks of Fungal mycelium (diameter of $6 \mathrm{~mm}$ ) prepared from growing margin of cultures of test isolate and placed in the center of PDA plates and at $30 \mathrm{~mm}$ distance from it, the Streptomyces disks (prepared as mentioned) were placed. Plates incubated at $27^{\circ} \mathrm{C}$ for $2-3$ weeks $^{[7]}$. Antifungal activity was indicative as mycelial growth of $B$. allii was 
prohibited in the direction of active Actinomycetes isolates. The level of inhibition at dual cultures was calculated by subtracting the distance $(\mathrm{mm})$ of fungal growth in the direction of an antagonist colony $(\gamma)$ from the fungal growth radius $\left(\gamma_{\circ}\right)$ of a control culture to give $\Delta \gamma=\gamma_{\circ} \gamma$. The ratings used were modified from those of Lee et $a l .{ }^{[5,8]}$, where $\Delta \gamma: 5-9 \mathrm{~mm}$, + (weak inhibition); $\Delta \gamma: 10-19 \mathrm{~mm},++$ (moderate inhibition); and $\Delta \gamma>20 \mathrm{~mm},+++$ (strong inhibition).

C- Well diffusion method: For evaluation of antifungal activity of aqueous samples, by use of sterile cork borer wells $(6 \times 4 \mathrm{~mm}, 2 \mathrm{~cm}$ apart) were punctured in fresh lawn cultures or at $30 \mathrm{~mm}$ distance from plugs of $B$. allii. Respective concentrations in dimethyl sulfoxide: Methanol (1/1: v/v) solvent (DM solvent) were then administered to fullness in each well. Plates were incubated at $24^{\circ} \mathrm{C}$ for $4-6$ days for lawn cultures and 14 days for dual culture disk-plugs. Bioactivity was determined by measuring inhibitory zones $(\mathrm{mm})$. Each experiment was repeated three times and the mean of inhibitory zones recorded. Controls included use of blank wells and use of DM solvent without test compounds ${ }^{[7]}$.

Chloroform assay for detection of antibiotic in Actinomycetes: Spore suspensions (approximately $10^{8}$ spors $\mathrm{mL}^{-1}$ ) of individual isolates were dotted $\left(10^{-6} \mathrm{~L} \mathrm{spot}^{-1}\right)$ onto $15 \mathrm{~mL}$ starch casein agar plates, five dots per plate. Plates were incubated at $28^{\circ} \mathrm{C}$ for 3 days $^{[9]}$. Dotted isolates were killed by inverting the uncovered Petri plates over $4 \mathrm{~mL}$ of chloroform in a watch glass for $1 \mathrm{~h}$. watch glasses were removed and plates were aerated in a fume hood for $30 \mathrm{~min}$ to permit evaporation of chloroform. Plates were subsequently overlaid with $15 \mathrm{~mL}$ of $1 \%$ water agar and inoculated with $10^{-6} \mathrm{~L}$ of test isolate, B. allii (approximately $10^{8}$ spors $\mathrm{mL}^{-1}$ ) spread uniformly over the surface of the agar. Plates were incubated at $24^{\circ} \mathrm{C}$ for $4-5$ days. The size of any zone of growth inhibition of the overlaid isolate surrounding any dotted isolate were measured in millimeters from the edge of the dotted colony to the edge of the cleared zone.

Scanning electron microscope studies: Mycelial morphology of Streptomyces isolate No. 347, the most active among other isolated Streptomyces, was showed with use of a scanning electron microscope model CAM SCAN-MV 2300. Preparation for the scanning electron microscope consisted of using the culture of 21-28 day old growing on CGA and depositing the specimens onto specimen aluminum stubs which held by a piece of double stick scotch tape. The stubs were coated in a sputter coater for $2 \mathrm{~min}$. Afterward the specimens were viewed and digital electron micrograph were prepared at magnification of 6000-20000 X with an accelerating voltage of $20 \mathrm{kv}$ accordingly.

Submerged cultures and preparation of crude extract: Streptomyces isolate No. 347 was grown in submerged cultures of CG medium on rotary shakers under $130 \mathrm{rpm}$ at $30^{\circ} \mathrm{C}$. To monitor the activity versus post seeding time, aseptically small aliquots of culture media were taken every $24 \mathrm{~h}$ for 27 days and the activity was evaluated by well diffusion-method ${ }^{[7]}$. To prepare crude extract, after 4 days of post seeding which the activity reached its maximum, the cultures were harvested; spores and mycelia were excluded by filtration through two layers of cheese cloth. The clarified sap was then dried to dark crude under reduced air at $50^{\circ} \mathrm{C}$, pulverized and kept refrigerated before use.

Solubility studies of active crude in organic solvents: To evaluate the relative polarity of the active principle (s) present in the crude, $2 \mathrm{~mL}$ of each of $\mathrm{H}_{2} \mathrm{O}$, methanol, acetone and chloroform were added to $20 \mathrm{mg}$ pulverized-crude samples separately and vortexed for $20 \mathrm{~min}$. Each sample was then centrifuged at $3000 \mathrm{rpm}$ for $15 \mathrm{~min}$. Supernatants and pellets were separated, dried under reduced air at $50^{\circ} \mathrm{C}$ and assayed at concentration of $10 \mathrm{mg} \mathrm{mL}^{-1}$ by well diffusion$\operatorname{method}^{[10]}$.

Determination of Minimum Inhibitory Concentrations (MIC): To measure the MIC value, two-fold serial dilutions of 50, 25, 12.5, 6.25, 3.125, 1.562 and $0.781 \mathrm{mg} \mathrm{mL}^{-1}$ of the crude extract were prepared in DM solvent and assayed by well diffusionmethod $^{[11]}$. The MIC was defined as the lowest concentration able to inhibit any visible fungal growth. All data represent average of three replicated experiments.

Determination of shelf life or stability of active crude: To measure the stability of the active crude in soluble state, $5 \mathrm{mg} \mathrm{mL}{ }^{-1}$ samples were prepared in distilled water and placed in small vials. These samples were kept at room temperature and tested using agar diffusion-method for anti $B$. allii activity at 14 days intervals as long as the activity persisted.

In vivo studies: The aim was to investigate the antagonistic effect of Streptomyces isolate No. 347 on control of onion gray mold caused by Botrytis allii. To prepare inocula, Streptomyces isolate No. 347 was cultured on CGA and B. allii was grown on PDA media. White onions disinfested by alcohol $70 \%$, dried 
and partially cut from fleshy below necks with sterile razor blades in two parts, smeared with spores using sterile cotton swabs, the two parts placed back in position and wrapped with Parafilm ${ }^{\circledR}$ to prevent dryness. Four treatments included: (a) control (untreated), (b) Botrytis allii alone, (c) Botrytis allii plus Streptomyces isolate No. 347 and (d) Streptomyces isolate No. 347 alone. Well grown lawn cultures of the pathogen and Streptomyces isolate No. 347 were used for spore inocula. For inoculation, spores of pathogen and/or Streptomyces were placed on appropriate cut surfaces by sterile cotton swabs and wrapped with Parafilm ${ }^{\circledR}$ as described and placed in four sterile capped transparent plastic boxes bearing ten bulbs in each and incubated at $24^{\circ} \mathrm{C}$. In the successive days, treated samples examined visually throughout the experiment for onset and progression of gray mold symptoms. To assess approximate percent of colonization, bulbs examined from eighth day after incubation and reexamined at intervals of four days for total of 28 days, successively. Based on the development of gray mold and extension of neck rot symptoms and spore colonization of treated bulbs, approximate percent of colonizations were recorded visually and mean values used for statistical analysis.

Data analysis: Analysis of variance and Tukey test of Post Hoc were used for analysis of recorded percentages of mean values. Significant factors in the univariate analysis at first step were entered to multivariate comparisons. Statistical analysis was performed with SPSS software package version 15.00 for windows. The significant level was set at $\mathrm{p}<0.05$.

\section{RESULTS}

Screening and bioassays: In screening for metabolites of soil Actinomycetes having antifungal activity against isolate of the cosmopolitan pathogen, B. allii, 50 isolates were screened from which 13 isolates showed high level of activity from which bioassay results of three most active isolates of 347, 263 and 350 are showed in Fig. 1.

Chloroform assay: Among 13 effective Streptomyces isolates, 3 isolates of 347, 263 and 350, retained their antifungal activities after exposure to chloroform.

Scanning electron microscope studies: Scanning electron micrograph of mycelia of Streptomyces isolate No. 347 is showed in Fig. 2. Streptomyces isolate No 263 has been previously identified as Streptomyces sindeneusis ${ }^{[10]}$.

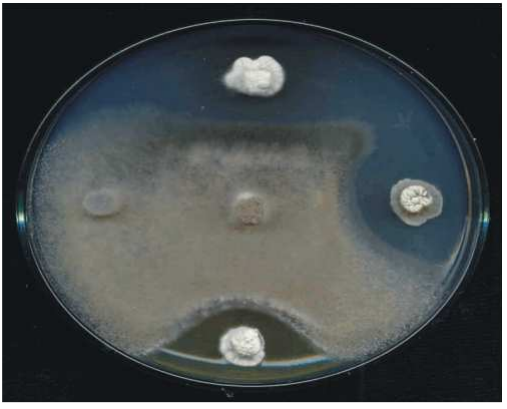

Fig. 1: Test result of screening using dual culture bioassay. Center, agar plug of Botrytis allii with radial growth; left, plain agar plug as control; right, Streptomyces isolate No. 347; top, Streptomyces isolate No. 263 and bottom, Streptomyces isolate No. 350 showing inhibitory effect against mycelial growth and sporulation of $B$. allii

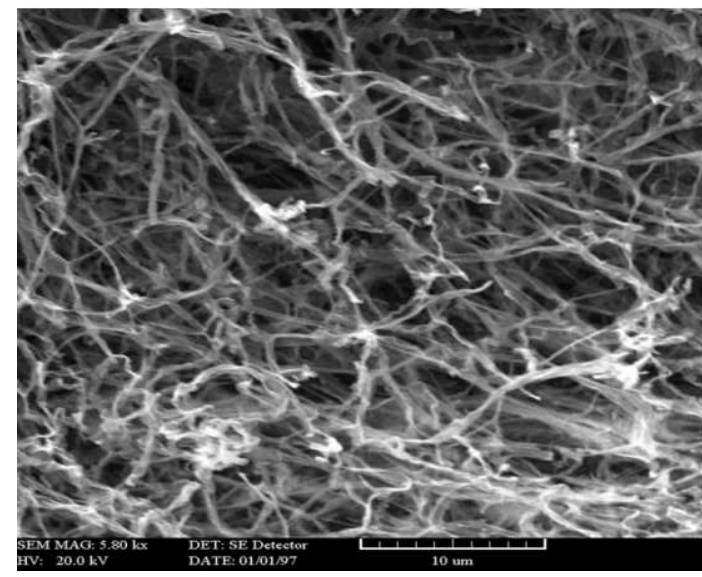

Fig. 2: Scanning electron micrograph of mycelia of Streptomyces isolate No. 347

Antifungal activity of submerged cultures: Activity versus post seeding time in submerged media cultures of Streptomyces isolate No 347 is showed in Fig. 3.

Since the activity reached its maximum after 4 days of post seeding, this time was used to harvest cultures for preparation of crude extract for further studies. Test result of bioactivity of aqueous culture medium of Streptomyces isolate No 347 in well diffusion method on lawn culture of Botrytis allii at the peak day is showed in Fig. 4. Crude extract was prepared by separating spores and mycelia via passing the culture media through two layers of cheese cloth and Whatman ${ }^{\circledR}$ filter paper and drying the filtrate to dryness using cold blower overnight. Prepared dried crudes were kept refrigerated before use. 


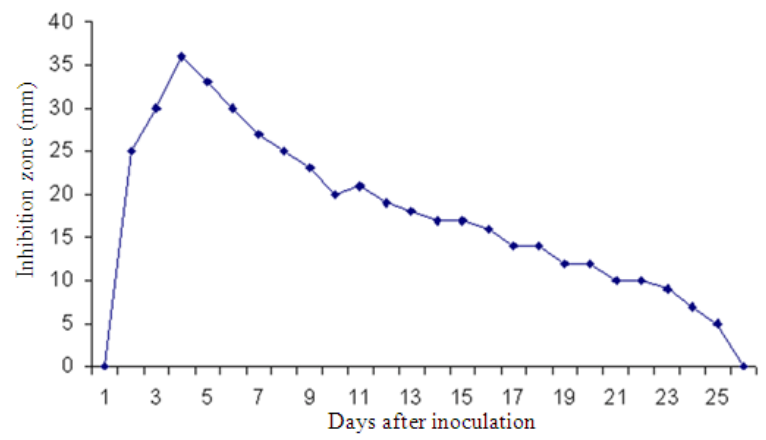

Fig. 3: Activity versus post seeding time in submerged cultures of Streptomyces isolate No. 347 monitored by well diffusion-method against Botrytis allii

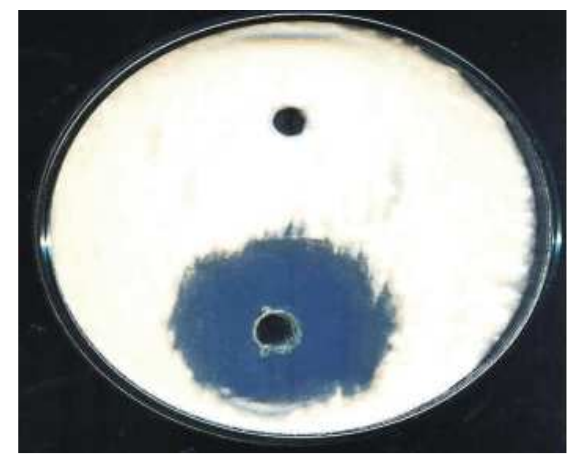

Fig. 4: Test result of bioactivity of aqueous culture medium of Streptomyces isolate No. 347 in well diffusion method on lawn culture of Botrytis allii; top, uninoculated culture medium as control and bottom, Streptomyces isolate No. 347 inoculated culture medium, 4th day after seeding of submerged medium showing inhibition of mycelial growth of $B$. allii

Solubility of active crude in organic solvents: Solubility results of crude extract of Streptomyces isolate No 347 are showed in Table 1. As the results show, apparently the active principle (s) has a polar nature since activity is recoverable only in $\mathrm{H}_{2} \mathrm{O}$ supernatants and pellets of tested organic solvent.

Determination of MIC: In well diffusion-method, MIC of the crude was determined as $0.05 \mathrm{mg} \mathrm{mL}^{-1}$ against $B$. allii.

Shelf life or stability of active crude: Stability of the active crude in distilled water at room temperature (12$30^{\circ} \mathrm{C}$ ) was about six months, assayed by using agar diffusion-method against $B$. allii.
Table 1: Bioassay results of solubility tests of the antifungal principle (s) of Streptomyces isolate No. 347 against Botrytis allii in fractions of different solvents indicated by well diffusion-method at $20 \mathrm{mg} \mathrm{mL}^{-1}$ of dry crude

\begin{tabular}{lll}
\hline Solvent & Fraction & Activity \\
\hline $\mathrm{H}_{2} \mathrm{O}$ & $\mathrm{S}^{\mathrm{a}}$ & + \\
\multirow{3}{*}{ Methanol } & $\mathrm{P}^{\mathrm{b}}$ & + \\
\multirow{2}{*}{ Chloroform } & $\mathrm{S}$ & - \\
& $\mathrm{P}$ & + \\
Acetone & $\mathrm{S}$ & - \\
& $\mathrm{P}$ & + \\
& $\mathrm{S}$ & - \\
\hline
\end{tabular}

a: Supernatant; b: Pellet; +: Soluble; -: Insoluble

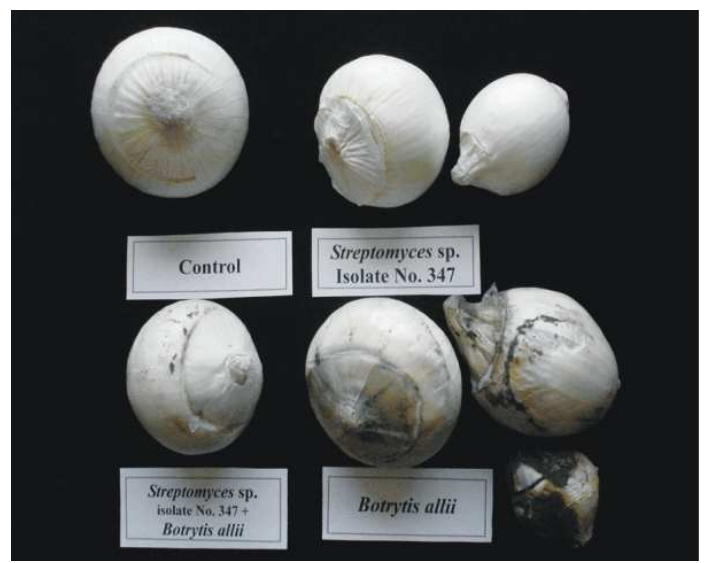

Fig. 5: Antifungal activity of Streptomyces sp. isolate No. 347 in control of Botrytis allii at $24^{\circ} \mathrm{C}$. Top left: control bulb, received no treatment; top right, bulb received only Streptomyces sp. isolate No. 347; bottom left: bulb received both Streptomyces sp. isolate No. 347 and B. allii and bottom right: bulb received treatment with $B$. allii

In vivo studies: The results of biological control of onion Botrytis gray mold in four tested treatments are shown in Fig. 5. Treatment of onion bulbs with pathogen resulted in development of typical gray mold symptoms which was progressive throughout the experiment. No visible symptoms developed in control or treatment of Streptomyces isolate No. 347 alone however, mild symptoms developed in treatment of B. allii plus Streptomyces isolate No. 347 which percentage of symptoms onsets recorded and used in statistical data analysis. Figure 6 shows antifungal antagonistic activity of Streptomyces sp. isolate No. 347 in control of Botrytis allii in neck rot of onion bulbs.

Statistical data analysis: Statistical analysis of data with multiple comparisons of Tukey test indicated which there was no significant difference between Streptomyces isolate No. 347 and control (untreated). 
Am. J. Agri. \& Biol. Sci., 4 (1): 72-78, 2009

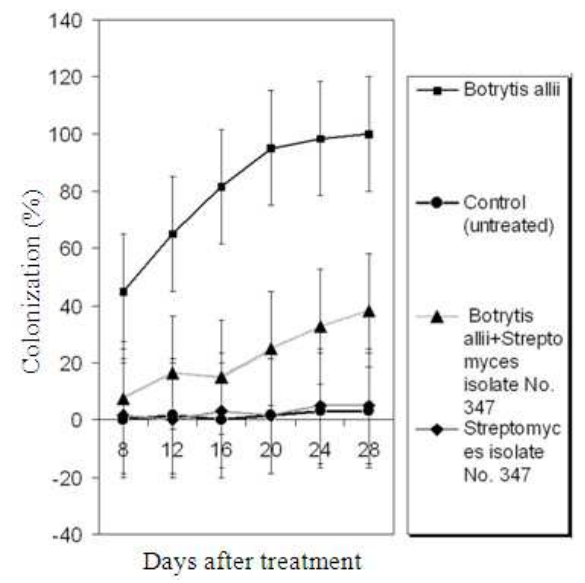

Fig. 6: Biocontrol of Botrytis gray mold by use of Streptomyces isolate No. 347. (a): Botrytis allii, (b): Botrytis allii plus Streptomyces isolate No. 347, (c): Control (untreated) and (d): Streptomyces isolate No. 347

Table 2: Multiple comparisons of four treatments in biocontrol of onion gray mold by Streptomyces isolate No. 347 by means of Tukey HSD test

\begin{tabular}{lll}
\hline & (J) Variable 1 & $\begin{array}{l}\text { Mean } \\
\text { difference (I-J) }\end{array}$ \\
\hline Botrytis allii & Control (untreated) & $79.1833^{*}$ \\
& $\begin{array}{l}\text { Botrytis allii }+ \text { Streptomyces } \\
\text { isolate No. 347 }\end{array}$ & $58.3000^{*}$ \\
& Streptomyces isolate No. 347 & $78.0667^{*}$ \\
Cotrytis allii & $-79.1833^{*}$ \\
& Botrytis allii + Streptomyces & $-20.8833^{*}$ \\
& isolate No. 347 & \\
& Streptomyces isolate No. 347 & -1.1167 \\
Botrytis allii + Streptomyces & Botrytis allii & $-58.3000^{*}$ \\
isolate No. 347 & control (untreated) & 20.8833 \\
& Streptomyces isolate No. 347 & 19.7667 \\
Streptomyces isolate No. 347 & Botrytis allii & $-78.0667^{*}$ \\
& Control (untreated) & 1.1167 \\
& Botrytis allii + Streptomyces & -19.7667 \\
& isolate No. 347 & \\
\hline
\end{tabular}

*: The significant level was set at $\mathrm{p}<0.05$.

However, there was significant difference between bulbs treated with $B$. allii plus Streptomyces isolate No. 347 and bulbs treated with $B$. allii at 0.05 level indicative of high level of antagonistic effect of Streptomyces isolate No 347 against Botrytis allii as shown in Table 2.

\section{DISCUSSION}

In sustainable agriculture natural biofungicides are safe and pro environment. Since most of synthetic fungicides do harm the ecosystem to some extent, their usage should be banned and switched to safer strategies as biological control techniques ${ }^{[10]}$. The pioneering work of Waksman showed that Actinomycetes are capable of producing medically useful antibiotics ${ }^{[12]}$. The purpose of this research was reducing gray mold damages by antifungal activity of Streptomyces isolate No 347. The results may also be considered for further studies of Actinomycetes microflora in native Iranian soils with the goal to find new agents in biocontrol of storage diseases of products. Post harvest diseases caused by phytopathogenic fungi such as Botrytis allii are of major problems in storage worldwide. Genetic engineering provides an opportunity to protect plants from fungal diseases and to reduce the use of chemical fungicides. The genes for antifungal metabolites from Streptomyces isolate No 347 can be engineered into onion plants to increase the resistance of the bulbs to fungal attack, decreasing the use of environmentally unfriendly fungicides in the field. The major factor limiting the application of this technology is the identification and isolation of useful genes that code for antifungal metabolites in Streptomyces isolate No 347. Further research of the project would be focused on field and long-term storage evaluation of the antagonist against the pathogen in the cosmopolitan malady of onion neck rot. As reported by Purvis et al. ${ }^{[4]}$, there are about 5 million units (50 pound bags) of low pungency, sweet onions produced in the Vidalia onion growing area at Georgia, USA, annually. Approximately half of them, 2.4 million units, are put in Controlled Atmosphere (CA) storage to extend the marketing period. Onions coming out of CA storage command a higher price, usually $\$ 20-24$ per unit compared to $\$ 10$ 14 (or less) per unit on the fresh market. Losses during storage range from $10-20 \%$ in good years to $50-70 \%$ in poor years. The primary cause of storage losses is rots from infection by the fungus, Botrytis allii.

\section{CONCLUSION}

Annual losses caused by Botrytis allii in storage can cost only in Vidalia onion growers from \$5-25 million. Genetically engineered onions bearing resistant genes against the pathogen would save the world money and produce, however, public concern on genetically engineered crops yet to receive special concern.

\section{ACKNOWLEDGMENT}

Thanks to Horticultural Research Institute of Shahid Bahonar University of Kerman for financial support. This research is part of MSc thesis of the first author and is dedicated to Mr. Afzalipour and Mrs. Fakhereh Saba, the founders of Universities in Kerman. 


\section{REFERENCES}

1. Warner, J., 2006. Onions and garlic may prevent cancers, healthy aging. http://www.myseniorsite.ca/health-garliconion.htm

2. Plant Disease Diagnostic Clinic at Cornell University, 2007. Botrytis blight. http://plantclinic.cornell.edu/FactSheets/botrytis/bo trytis_blight.htm

3. Schwartz, H.F. and M.E. Bartolo, 2007. Onion, Diseases, Fungal diseases, Botrytis Diseases. http://scarab.msu.montana.edu/HPIPMSearch/docs/ botrytisdisease-onion.htm

4. Purvis, A.C., J. Brock and J.T. Paulk, 2002. Does Botrytis spread to sound onions in storage? Vidalia onion research laboratory, University of Georgia Tifton Campus. http://www.cpes.peachnet.edu/vorl/Storage\%20Dis eases.htm

5. Lee, J.Y. and B.K. Hwang, 2002. Diversity of antifungal actinomycetes in various vegetative soils of Korea. Can. J. Microbiol., 48: 407-417. http://www.ingentaconnect.com/content/nrc/cjm/20 02/00000048/00000005/art00004?crawler=true

6. Shahidi Bonjar, G.H., P. Rashid Farrokhi, S. Bafti, S. Aghighi, M.J. Mahdavi and A. Aghelizadeh, 2006. Laboratory preparation of a new antifungal agent from Streptomyces olivaceus in control of Fusarium oxysporum f.sp. melonis of cucurbits in greenhouse. Am. J. Applied Sci., 6: 607-610. http://scialert.net/asci/ascidetail.php?doi=jas.2006. $607.610 \& \mathrm{kw}=$

7. Aghighi, S., G.H. Shahidi Bonjar, R. Rawashdeh, S. Batayneh and I. Saadoun, 2004. First report of antifungal spectra of activity of Iranian Actinomycetes strains against Alternaria solani, Alternaria alternate, Fusarium solani, Phytophthora megasperma, Verticillium dahliae and Saccharomyces cerevisiae. Asian J. Plant Sci., 3: 463-471. DOI: 10.3923/ajps.2004.463.471
8. El-Tarabily, K.A., M.H. Soliman and A.H. Nassar et al., 2000. Biological control of Sclerotinia minor using a chitinolytic bacterium and actinomycetes. Plantpathology, 49: 573-583. DOI: $10.1046 /$ j.1365-3059.2000.00494.x

9. Davelos, A.L., L.L. Kinkel and D.A. Samac, 2004. Spatial variation in frequency and intensity of antibiotic interactions among streptomycetes from prairie soil. Applied Environ. Microbiol., 70: 1051-1058. DOI: 10.1128/AEM.70.2.1051-1058.2004

10. Ebrahimi Zarandi, M., G.H. Shahidi Bonjar, F. Padasht Dehkaei, S.A. Ayatollahi Moosavi, P.R. Farokhi and S. Aghighi, 2009. Biological control of rice blast (Magnaporthe oryzae) by use of Streptomyces sindeneusis isolate 263 in greenhouse. Am. J. Applied Sci., 6: 194-199. http://www.scipub.org/fulltext/ajas/ajas61194-199.pdf

11. Shahidi Bonjar, G.H. and A. Karimi Nik, 2004. Antibacterial activity of some medicinal plants of Iran against Pseudomonas aeruginosa and $P$. fluorescens. Asian J. Plant Sci., 3: 61-64. http://www.doaj.org/doaj?func=abstract\&id=314051

12. Augustine, S.K., S.P. Bhavsar and B.P. Kapadnis, 2005. Production of a growth dependent metabolite active against dermatophytes by Streptomyces rochei AK 39. Indian J. Med. Res., 121: 164-170. http://www.ncbi.nlm.nih.gov/pubmed/15802758?d opt=Abstract 